\title{
'It is difficult to think about becoming what you have never seen': Black students' reflections around a career in academic dentistry
}

\author{
Catherine Coelho, ${ }^{* 1}$ Obioma Ukoha, ${ }^{1}$ Vivien Onamusi, ${ }^{1}$ Rachel Ogunleye, ${ }^{1}$ Yewande Oduwole, ${ }^{1}$ Christopher Tredwin, \\ Helen Watson ${ }^{1}$ and Sally Hanks ${ }^{1}$
}

\section{Key points}

Not only are Black people under-represented in dentistry as a whole compared to their percentage of the population, the percentage of Black academics who teach dentistry to an increasing number of aspiring young Black

students is negligible.
Knowing how to pursue a career in academic dentistry could be seen as daunting to all, but the low visibility of Black academics compounds this for the population of Black students.
All dental academics can foster a career in academia as a prime career choice by providing mentoring opportunities, support and role models to all dental students, and especially those Black students who want to change this landscape.

\begin{abstract}
This opinion piece considers the national representation of the Black population in the United Kingdom in an academic career in dentistry and draws on engagement with Black dental students to see what their perceptions of this are. Black people are under-represented in dentistry as a whole and the number of Black academics who teach dentistry to an increasing number of aspiring young Black dental students is exceedingly low. Black dental students do not see themselves represented by their teachers and therefore 'it is difficult to think about [them] becoming what [they] have never seen'. Black dental students themselves have started initiatives to establish a strong support network of aspiring and qualified Black dentists. Dialogue with them showcases that while there are pathways into an academic career in dentistry, these appear unclear to them. This piece is intended to raise awareness of these issues, in the knowledge that with mentoring, role modelling and dialogue, pathways may become clearer, opportunities may arise that were previously not considered and the national picture may one day change.
\end{abstract}

\section{Introduction}

The Windrush scandal, the murder of George Floyd and the subsequent worldwide resurgence of the Black Lives Matter movement have all raised societal consciousness around what it is like to be Black in the United Kingdom. It seems prudent and timely to consider what this means for the Black dental students in this country and what their thoughts are regarding their careers within dentistry. Perspectives on what it means to be an aspiring Black dental student in this country and reported evidence of prejudice towards Black students have been shared. ${ }^{1}$ This has led us to scrutinise to what

'University of Plymouth, Faculty of Health Peninsula Dental School, Room C502, Portland Square, Drake's Circus,

Plymouth, PL4 8AA, UK.

*Correspondence to: Catherine Coelho

Email address: cathy.coelho@plymouth.ac.uk

Refereed Paper.

Accepted 18 October 2021

https://doi.org/10.1038/s41415-022-3879-5 extent (if any) Black dental students consider following an academic career path, with a view to challenging discrimination and promoting positive change and equality.

For the purposes of this opinion piece, we are using the Collins dictionary's definition of an academic as 'a member of a university who teaches or does research', and our use of the term 'academic' refers to those who are faculty and whose primary place of employment is within a university. We are not including dental tutors with a supervisory role within a university dental school and whose main employment is within another setting; for example, primary dental care.

The statistical national picture appears to demonstrate a concern that Black students are not taking such strides into academic careers in dentistry:

- The Black ethnic group, at $3.4 \%$, is the third largest percentage of the population in England and Wales, behind the Asian ethnic group at $7.5 \%$ and the white ethnic group at $86.0 \% .^{2}$ These data are a decade old and a more recent census of England and Wales took place in March 2021. The Office for National Statistics aims to publish some headline national and local authority-level outputs within one year of the census date, and all other 'main data' within two years

- In 2017, the total number of dentists who identified as Black or Black British in the UK was $1 \%^{3}$

- Between 2006 and 2020, Black pupils had the biggest increase in entry to higher education out of all ethnic groups, from $21.6 \%$ to $47.5 \% .{ }^{4}$ However, only $3.7 \%$ of this group study dentistry ${ }^{5}$

- Within dentistry, just $1.1 \%$ of the 607.3 fulltime equivalent (FTE) clinical academics employed at UK dental schools identified as Black in $2017^{6}$

- The level of seniority by academic grade of clinical academics employed at UK dental schools increases for those who identify as white. Clinical academics who identify as 
Black, Indigenous and People of Colour (BIPOC) are most under-represented at professorial level at $8.5 \%$, with $91 \%$ identifying as white. ${ }^{6}$ It is not known from these data what percentage of those at professorial level are Black

- Within higher education, $17 \%$ of all academic staff identify with a known ethnicity of BIPOC, although it is not known from these data what percentage of these are Black. ${ }^{7}$

So, not only are Black people underrepresented in dentistry as a whole compared to their percentage of the population, the percentage of Black academics who teach dentistry to an increasing number of aspiring young Black students is woeful.

Our local picture is similar. The majority ethnic background of dentistry students at the University of Plymouth Peninsula Dental School, for the academic year 2020/21, was Asian at $49 \%$; the proportion of white students was $38 \%$, with Black students making up $6 \%$. There are currently no academic staff at Peninsula Dental School that identify as Black. Eighty-eight percent of staff identify as white and $2 \%$ of staff identify as Asian. We do, however, recognise that our locality may not be as demographically representative as other more diverse communities and it would be useful to look at comparative data from other dental schools in the future.

Recognising that the ethnic backgrounds of our staff do not represent that of our students, we were motivated to find out what we could do to encourage Black students to pursue a career in academic dentistry. We arranged to meet with members of the social media group 'Budding Black Dentists', a number of whom were known personally to us as current students and members of our alumni. We met with some of them on an informal basis to explore what they knew about academic dentistry and what they perceived as being the barriers or enablers to a career in this field. We also contacted a recent alumnus from our institution to gain a perspective of their journey from beyond dental school.

Budding Black Dentists is a platform founded by a 2021 graduate dental student from the University of Plymouth Peninsula Dental School, who not only noticed the worrying lack of Black representation in the field of dentistry, but also felt the need to target this issue. She and two of her colleagues from Peninsula Dental School attended a national dental student conference and found that they were among only a handful of Black dental students present. This was not the case for those of Asian and white backgrounds. This meant that finding mentorship as a young Black dental professional in the hands of someone that looked like them would be near impossible. In an attempt to combat this, the three students launched Budding Black Dentists, a non-profit organisation with the following aims:

- To equip aspiring dental applicants with the necessary tools needed for each stage of their dental journey

- To help to educate the Black community, via outreach programmes, on the importance of oral health and what dentistry entails

- To establish a strong support network of aspiring and qualified Black dentists to act as mentors.

Budding Black Dentists now has members from a number of dental schools.

\section{Our findings from talking to students and alumni}

On talking to the founding member and three current student members, all from the University of Plymouth Peninsula Dental School of the Budding Black Dentists, they were very appreciative of the opportunity to discuss the issues. They came from closeknit communities but had no dentists within their families. There were consequently no Black dental role models to aspire to be like, meaning these students had a low social capital on which to build their careers. Their first experience of a Black lecturer was in the third year of studying, and they remembered noting that it had taken this long for them to see someone who looked like them. They acknowledged that they feel they are the generation that will have to make this change and they want to make this change.

There was an intrinsic misunderstanding about what a career in academia actually meant, although they understood about dental core training and dental speciality training such as orthodontics. NIHR Academic Clinical Fellowships were an unknown career choice. They identified the dental school academics as the 'management team' and did not define them as having a career in academic dentistry. Further meetings with students from all ethnicities are needed to ascertain if this is pertinent to all or dependent on ethnicity.

Mentoring around careers was discussed in depth and was seen as being especially valued. The group felt that mentors did not necessarily need to be from the same ethnic demographic but they needed to have a sound knowledge of relevant career paths and needed to come with solutions to possible career destinations as well as information.

There was cogency and enthusiasm to influence change but a strong feeling that help is needed to provide direction and support to overcome what was seen as the main barrier to a career in academia: few or no visible role models to ignite that spark of interest in even contemplating a career in academia. Little or no knowledge about what dental academics do, or how to go about following that career path, underpinned this viewpoint. Again, this may be a widely held perception from all students and further discussion is needed to explore this.

Our alumnus, who was Black, echoed the words of our current students and talked about the invisibility and subsequent normality of not having academics teaching her who looked like her. The unclear path into academia was cited but the overall message was positive, with the current younger generation of Black dentists being the ones with the impetus and drive to enact change.

\section{University of Plymouth Peninsula Dental School's Budding Black Dentists representatives' reflections on a career in academia}

" II am the first Black dentist I've ever met". I used to say this in my first year of dental school, though this wasn't strictly true, seeing as I was not and still am not a qualified dentist, but the sentiment remained the same. At this time in dental school, I had not yet encountered a qualified Black dentist, and I felt very strongly that the other Black people in the dental school and I were entering uncharted waters. Thankfully I have now met Black dentists, thanks to Budding Black Dentists and the AfroCaribbean Dental Association, and this has changed my experience in university and my future prospects for the better. My hope is that Black students that attend dental schools after me will be able to see themselves in the world of dentistry more organically, through their academic teams, as their teachers, lecturers and professors. 
'I have never been taught, in a university setting, by a Black dental academic, and until my third year of university, I had never been taught by a Black person at all. So, when Dr Catherine Coelho asked us if we have ever considered $a$ career in academia, the answer I had was "no". At this point, I had never considered a career in academia, simply because it's difficult to become what you have never seen. I have never seen Black dentists enter academia, not because they don't exist, but because there are so few. I think it subconsciously led me to believe this is an area of dentistry that Black people either can't or don't do, and I internally opted myself out of academia. This is how lack of diversity in a profession can be self-perpetuating if nothing is implemented - there are few Black people in a profession, so due to lack of representation, few Black people enter the profession, and the small percentage of Black people in the profession remains and continues.

Increasing the number of Black dentists in academia is important for greater representation in clinical, educational and research areas, and not just for the future career prospects of the Black students attending universities, but for healthcare as a whole. Culturally competent healthcare is defined as 'the ability of systems to provide care to patients with diverse values, beliefs and behaviours, including the tailoring of healthcare delivery to meet patients' social, cultural and linguistic needs. ${ }^{8}$ To be able to provide this type of healthcare, students must be taught by a diverse range of educators who can teach from their wealth of experiences and their own cultural lenses. Without Black academics, it may be more difficult for future dentists to provide culturally competent healthcare.

Academia, as a student, seems to be a well-kept secret. At university, students are introduced to many different specialities and the route into each of them, respectively; however, we as students have never been given any information about how to enter academia. Even when you search for the information via Google, the information you find about becoming a lecturer or professor in dentistry is very complex or incredibly vague. This is an issue for anyone trying to enter this field, including Black dentists and dental students that are considering academia.

\section{Perspectives from beyond dental school}

A career in academia is one that is often not widely considered by students generally, let alone Black students. There seems to be a lack of guidance for those who wish to go down this route. It is becoming clearer as the years go by that dentistry is a small profession and often opportunities can be based on "who you know, rather than what you know". Humans tend to generally align with people that are from similar backgrounds as them and unconscious bias can play a role in decision-making when these positions become available.

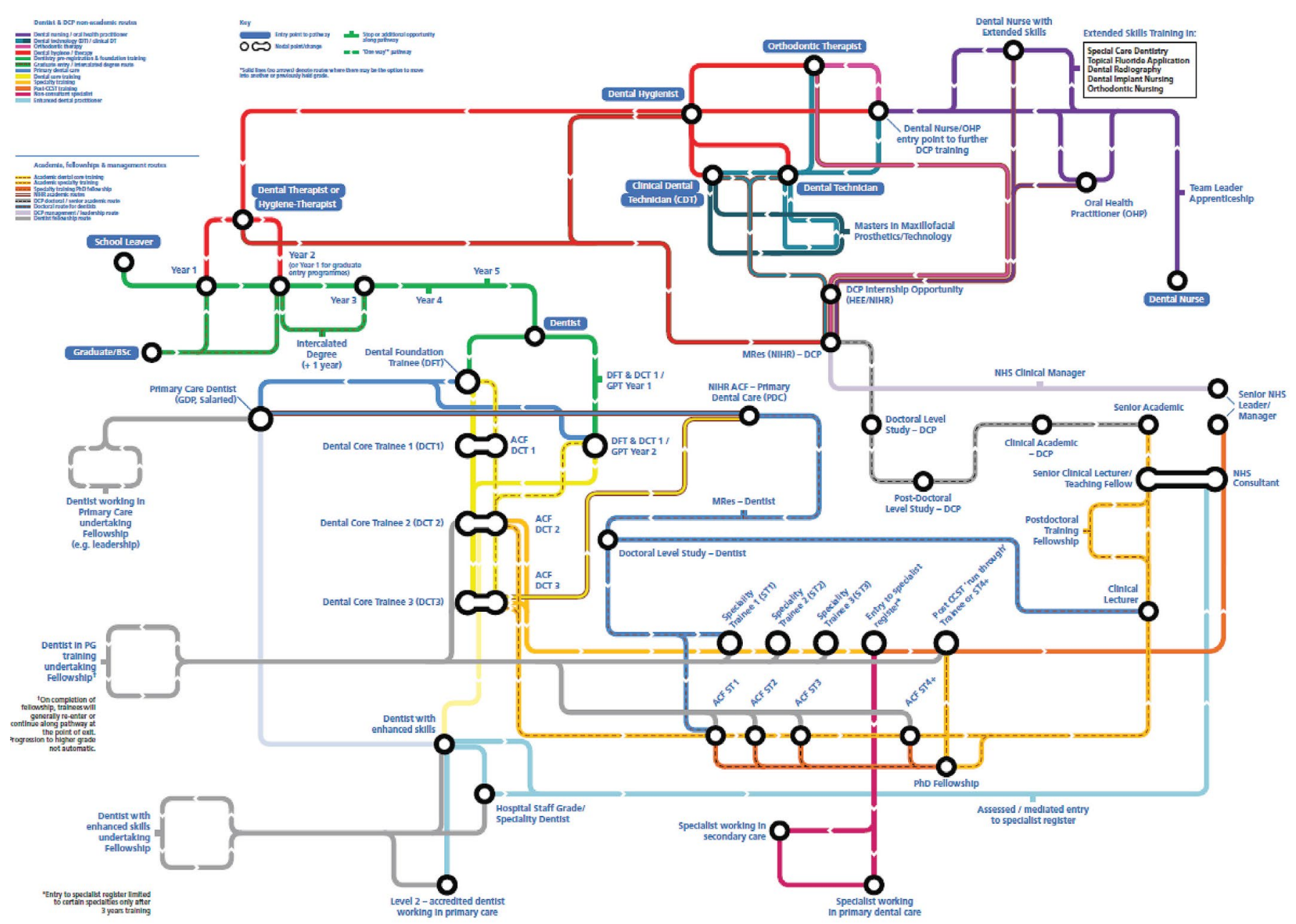

Fig. 1 Tube map for a career in academic dentistry, reproduced with permission from Health Education England (note this was an engagement tool and does not represent the final ADC model) 
'This can automatically put Black dentists at a disadvantage. My earliest memory of noticing this was during my interview into dental school, I remember walking into a room to a panel where no one looked like me. These thoughts continued during dental school when being taught clinical and academic sessions. It eventually became normal to not see any Black academics and it would be surprising if I ever did come across one.

'However, this should certainly not be the case. I believe that it's not that Black dentists do not qualify for these academic roles, it's just the roles are invisible to strive for in the first place. On a positive note, I believe that our generation in particular have the tools and resources to put ourselves out there more. People are starting to share opportunities and information online with one another on social media platforms, which can have a profound effect. I took to YouTube to create videos so young Black aspiring students in particular could see someone that looked like them in the field. This has proved to be successful and I have since had many apply to dentistry because of this. I feel that over time this will be the case with academia, the more diverse it becomes the more students will feel inspired to go down that route.

\section{Solutions}

The statement 'it is difficult to think about becoming what you have never seen' epitomises the message we wish to convey - and while we recognise that not every dental student, of any ethnicity, may wish to pursue a career in academia, by building a more ethnically diverse academic workforce, especially at higher levels such as professorial level, this may give young dentists a wider vision of what career choices are available. Increasing the number of Black dental academics will not be quick but there are strategies that can be initiated to expedite the process. A multifaceted approach is needed with the impetus for change coming from academics as a whole, working alongside students and graduates who want change. Academics need to be explicit about what they do and extol the value of a career in training their future replacements. Articulation of their career journeys and choices available to them within each UK dental school would go a long way to clarify career pathways and options.

Phase II of the Advancing Dental Care (ADC) Review has a clear workstream to develop and promote academic careers, and it notes the 'academic training pathway is

\section{Fig. 2 BDA Career guide - general overview of careers in dentistry, reproduced with permission from the British Dental Association}

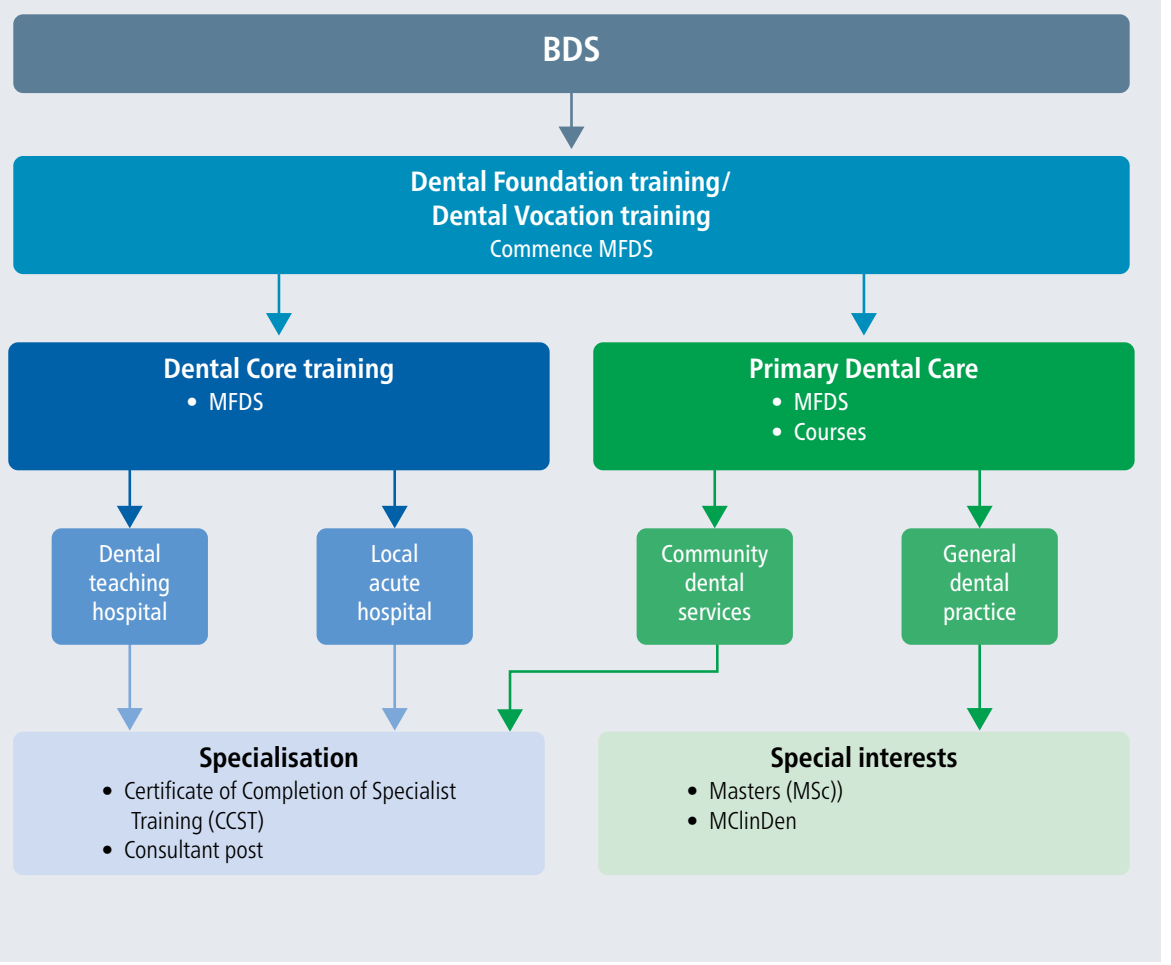

perceived to be complicated and careers of clinical academics is not always understood. ${ }^{9}$ The training pathways, or 'tube maps', in the ADC Review are complex (Fig. 1) and may appear daunting to dentists with little prerequisite knowledge of all the various strands. At the other end of the spectrum, the BDA Career Guide does not mention academia within its general overview of careers in dentistry (Fig. 2). A middle ground is needed that is accessible and understandable for students without being too simplistic.

The NIHR Academic Clinical Fellowship (ACF), a clinical speciality training post in dentistry that incorporates academic training, has started the journey of making access to a career in academic dentistry easier. However, with allocated funding for only 23 ACFs for recruitment in 2021/22, this compares poorly with the 119 speciality training places for orthodontics, for example.

However, none of these make explicit recommendations to change the percentage of Black clinical academics employed at UK dental schools.

We feel the impetus for change to the proportion of Black dental academics needs to come from visible representation within UK dental schools themselves. Prioritising this can come from all facets of a dental school, whether that be faculty, professional services or students. Transparent equality and diversity processes from the first stages of recruitment through to career promotion is fundamental in encouraging all aspiring Black dental academics. The hope is that by highlighting this issue, it becomes incumbent on all of us who are dental academics, and not just Black academics, to take this responsibility upon ourselves. We need to develop a dialogue that not only fosters a career in academia as a prime career choice, but provides mentoring opportunities, support and role models.

There are no conflicts of interests.

\section{Author contributions}

All authors contributed, reviewed and inputted to this paper. All authors are affiliated with the University of Plymouth, either as faculty, current dental students or alumni.

\section{Acknowledgements}

The authors would like to acknowledge all members of the Budding Black Dentists group, and especially their founder Elizabeth Fynn-Famoden, for not only noticing a different experience for Black dental students and acting upon that, but for having the vision to drive change in this area.

\section{Ethics declaration}




\section{References}

1. Kadiyo T, Mellish V. Black Lives Matter: the impact and lessons for the UK dental profession. Br Dent J 2021; 230: 134-142.

2. Office of National Statistics. Ethnicity and National Identity in England and Wales: 2011. 2012. Available at http://www.ons.gov.uk/ peoplepopulationandcommunity/culturalidentity/ ethnicity/articles/ethnicityandnationalidentity inenglandandwales/2012-12-11 (accessed October 2021).

3. General Dental Council. Annual Report and Accounts 2016. 2017. Available at https://www. gdc-uk.org/docs/default-source/annual-reports/ gdc_annual_report_2017-(2).pdf (accessed October 2021).

4. UK Government. Entry rates into higher education. 2021. Available at https://www.ethnicity-facts-figures. service.gov.uk/education-skills-and-training/highereducation/entry-rates-into-higher-education/latest (accessed October 2021).

5. Higher Education Statistics Agency. Table 8 - UK domiciled HE student enrolments by subject of study and ethnicity. 2017. Available at https://www.hesa. ac.uk/data-and-analysis/students/what-study/ characteristics (accessed October 2021).

6. Watson N, Tang P, Knight E. Survey of Dental Clinical Academic Staffing Levels. London: Dental Schools Council, 2018.
7. Higher Education Statistics Agency. Ethnicity of staff. 2020. Available at https://www.hesa.ac.uk/ news/23-01-2020/sb256-higher-education-staffstatistics (accessed October 2021).

8. Health Research \& Educational Trust and Institute for Diversity in Health Management. Building a Culturally Competent Organisation: The Quest for Equity in Health Care. 2011. Available at http://www.hpoe.org/Reports-HPOE/ culturalcompetentorgslides7.2011.pdf (accessed October 2021).

9. Health Education England. Advancing Dental Care Phase II. 2020. Available at https://www.hee.nhs.uk/ our-work/advancing-dental-care/advancing-dentalcare-phase-ii (accessed October 2021). 